\title{
WORKER RESPONSE TO A MENU OF IMPLICIT CONTRACTS
}

\author{
DON BELLANTE and ALBERT N. LINK*
}

\begin{abstract}
The literature on implicit contracts between workers and firms suggests that workers face a variety of such contracts, allowing each to choose the optimal trade-off between earnings level and earnings stability. This study tests some implications of that theory through an examination of the risk behavior of individual heads of households. The data source is the University of Michigan Panel Study of Income Dynamics, which includes a measure of the worker's taste for risk avoidance. Additionally, several predictions derived from Arrow's postulate of increasing relative risk aversion are examined. The results confirm a tendency of risk-averse individuals to choose jobs offering lower wages and lower financial risk. The results also provide indirect support for Arrow's postulate. The paper's findings suggest that studies of the earnings effects of discrimination may possibly understate those effects, just as studies of the value of a human life may understate that value.
\end{abstract}

\section{A} NUMBER of articles appeared almost simultaneously in $1974-75$ on the subject of implicit contracts between workers and firms. ${ }^{1}$ All sought to provide a rationale based on utility-maximizing be-

\footnotetext{
-Don Bellante is a professor of economics at Auburn University and Albert Link is a professor of economics at the University of North Carolina at Greensboro. They appreciate helpful comments on earlier versions by Timothy Deyak, Robert M. Feinberg. Barry Hirsch, Fred Johnson, James E. Long, and J. Wilson Mixon.

${ }^{1}$ Costas Azariadis, "Implicit Contracts and Underemployment Equilibria," Journal of Political Economy, Vol. 83, No. 6 (November/December 1975), pp. 1183-1202; Martin Baily, "Wages and Employment under Uncertain Demand," Review of Economic Studies, Vol. 41, No. 1 (January 1974), pp. 3750; and Donald F. Gordon, "A Neo-Classical Theory of Keynesian Unemployment," Economic Inquiry, Vol. 12, No. 4 (December 1974), pp. $431-59$.
}

havior to explain the phenomenon of wage inflexibility. These and the works that have followed are a major contribution to the solution of several paradoxes, problems, and inconsistencies of macroeconomics. One of the key tenets of contract theory is that wage inflexibility is the result of optimal firm behavior rather than the money illusions and invidious comparisons of relative wages by workers that were central to earlier Keynesian thought. Rather than being seen as "taking advantage" of cyclical variations in demand, as in an auction market, the firm is viewed as offering stability to the large majority of workers in exchange for lower mean wages. The optimal mean wage-stability combination from the perspective of a firm depends on characteristics (such as stability of its industry's product demand) 
that vary across firms. ${ }^{2}$ Consequently, as Gordon points out, we should expect to see the labor market characterized by a variety of degrees of risk sharing between workers and firms-in effect, a "menu" of implicit contracts. ${ }^{3}$

The recognition of such a menu is in a sense nothing new to economists. Numerous studies of income distribution provide empirical evidence of a trade-off between earnings and security-or, more precisely, a positive relation between mean earnings and variability of earnings by occupation. ${ }^{4}$ Indeed, economists since Adam Smith have speculated that the degree of financial risk inherent in a particular occupation (as with other nonpecuniary job characteristics) should bring forth an "equalizing difference" in the wage for that occupation sufficient to compensate the marginal worker for that risk. For nearly two centuries this basic proposition regarding equalizing differences was accepted in principle but no empirical evidence was sought: perhaps not only because of data availability problems but also because of a presumption that the forces determining wage differences were simply too complex. ${ }^{5}$ Even in recent specu-

\footnotetext{
'Stability, of course, can come in the form of either wage or employment stability. However, the conditions under which employment stability would totally dominate (resulting in full-employment contracts) are highly restrictive and unlikely, as demonstrated by Azariadis, "Implicit Contracts."

${ }^{3}$ Gordon, "A Neo-Classical Theory of Keynesian Unemployment," pp. 449-50.

${ }^{4}$ See, for example, Allan G. King, "Occupational Choice, Risk Aversion, and Wealth," Industrial and Labor Relations Review, Vol. 27, No. 4(July 1974), pp. 586-96; and Paul Taubman, Sources of Inequality in Earnings (Amsterdam and New York: North Holland and American Elsevier, 1975), pp. 95-111.

${ }^{3}$ Most studies of nonwage characteristics use the hedonic methodology as applied to the labor market by Richard Thaler and Sherwin Rosen in "The Value of Saving a Life: Evidence from the Labor Market," in Nestor Terleckyj, ed., Household Production and Consumption (New York: National Bureau of Economic Research, 1975), pp. 265-98. Feinberg, for example, after controlling for personal characteristics, found that each one percent difference in the coefficient of variation of the wage rate is positively associated with a $\$ .0435$ difference in the hourly wage rate. The mean hourly wage rate of his sample is $\$ 4.91$, indicating an elasticity at the mean of approximately +.89. See Robert M. Feinberg. "Earnings-Risk as a
}

lation, the empirically observable differential that compensates for risk has been discussed as if it were generated entirely from the labor-supply side of the market; firms in industries with "inherently" highly variable earnings have no choice but to pay the wage premium demanded if they are to attract the requisite number and quality of employees. Contract theory recognizes the ability of firms to "sell insurance" against such variability and suggests the determinants of the terms of such contracts. Expositions of implicit contract theory, however, do not consider the variation in workers' responses to the menu of contracts; that is, workers are assumed to be homogeneous with regard to taste for risk. ${ }^{6}$ Such an assumption does not allow predictions to be made about the micro behavior of laborforce participants in response to the menu: specifically, the issue of which workers will accept which contracts is left unexplored.

One purpose of this paper is to examine the determinants of risk choice by individuals. Of particular interest is the-relation between job choice and variation in individual taste for risk. The analysis is cast in terms of a job-choice model in which the selection of a particular occupation-industry combination is viewed as a selection of a certain amount of risk. Implicit in contract theory is the conclusion that the offering of a menu of contracts is more efficient (not only from the perspective of employers, but also from that of workers) than would be the absence of such contracts. Yet such a conclusion would follow only if workers are viewed as choosing jobs as if they have perceived and rationally acted upon their available choices. Our analysis will also shed light on this question. In the remainder of this paper we formulate and test a simple theoretical model of risk choice.

\section{Utility Maximization and Risk Choice}

In what follows, we present a utility. maximization model of job choice. An individual in selecting a job implicitly chooses a set of job characteristics, each of which

Compensating Differential," Southern Economic Journal, Vol. 48, No. 1 (July 198I), pp. 156-63.

${ }^{6}$ Azariadis, "Implicit Contracts," p. 1186. 
affects the individual's total utility. Given the idiosyncratic nature of labor markets occurring as a consequence of differences in specific training, workers are assumed for simplicity to make a once-in-a-lifetime choice of occupation and industry. Other simplifying assumptions are that individuals' formal education (general training) is completed before final job selections are made; that individuals have knowledge of the distribution of lifetime earnings (with regard to the mean and variance) within each occupation-industry combination but have no knowledge of where their income will fall along that distribution; and that workers expect intertemporal stability in the ordering of means and variances of earnings across occupation-industry categories.

Financial risk (random variability in earnings) is introduced as a direct argument in the utility function; specifically, financial risk (hereafter referred to as risk) is treated as an economic "bad." Our use of the term risk refers to earnings variability due not only to variation in the rate of pay, but also to the influence of unemployment. The designation of risk as a "bad" facilitates the conceptualization of a concave indifference curve showing the trade-off between risk and mean earnings. ${ }^{7}$ Some controversy exists over the indifference-curve approach. Although we maintain the concept of a concave "good" versus "bad" tradeoff, we note below the implications of that controversy for our analysis.

Assume an individual chooses an occupation-industry combination so as to maximize total lifetime utility $U$ :

$$
U=U(W, R, C),
$$

where $W$ is expected lifetime earnings (expressed as an annual rate), $R$ is the coefficient of variation of earnings associated with a particular job choice, and $C$ is a vector of other nonwage, job-related characteristics. ${ }^{8}$ Following convention, it is assumed

\footnotetext{
${ }^{7}$ The use of such an indifference curve was popularized (in the context of portfolio selection) by James Tobin in "Liquidity Preference as Behavior Toward Risk," Review of Economic Studies, Vol. 25, No. 2 (February 1958), pp. 65-85.

${ }^{8} \mathrm{We}$ are assuming that the standard workweek within an occupation-industry is employer-deter-
}

that $U^{\prime}(W)>0 ; U^{\prime \prime}(W)<0$; and, assuming risk aversion, $U^{\prime}(R)$ and $U^{\prime \prime}(R)<0$.

If labor markets are dominated by the risk averse, as available evidence suggests, then an individual with given productivityrelated characteristics will face an opportunity locus exhibiting a positive relation between mean earnings, $W$, and riskiness of earnings, $R$, across occupational categories. This relation, assumed for simplicity to be linear, forms the multidimensional menu of implicit contracts as:

$$
W=a+b R+\sum_{i=1}^{n} d_{i} C_{i},
$$

where $n$ is the number of nonwage characteristics (other than risk) for which equalizing differences exist. The constant term, $a$, can be thought of as the competitive riskfree pure return on the given amount of human capital possessed by the individual. By maximizing Equation l subject to Equation 2, we yield the following relationship among first-order conditions:

$$
U^{\prime}(W)=-U^{\prime}(R) / b=U^{\prime}\left(C_{i}\right) / d_{i}=\lambda,
$$

where $\lambda$ is a Lagrangian multiplier. It follows that utility maximization requires that the rate at which individuals can acquire additional annual earnings by accepting additional risk be equal to the rate at which they are willing to do so: $b=-U^{\prime}(R)$ $/ U^{\prime}(W)$. Of two individuals facing the same opportunity locus and whose utility functions differ only in their tastes for risk, the more risk-averse individual will choose a point on the opportunity locus representing a lower wage and a lower degree of variability in earnings than the point chosen by the other individual.

Trade-offs can be derived between $R$ and the various $C_{i}$ 's (nonwage job characteristics); however, these relationships besides being obvious are of minor interest since, across individuals, there is generally no a priori expectation of a correlation between the taste for financial risk and the taste for various $C_{i}$ 's. One exception is job-related

mined as in Ronald G. Ehrenberg, Fringe Benefits and Overtime Behavior (Lexington, Mass.: Lexington Books, 1971), p. 5. Hence the employee's choice of work hours for the most part is implicit in the job choice. 
safety. Conceivably, an individual with a relatively high aversion to risk may be willing to pay a higher premium (that is, accept a lower wage) to avoid both financial and physical risk. Consequently, an individual with a given degree of risk aversion will accept greater financial risk in a job choice only if lower physical risk is obtained.

Individuals will, of course, face widely differing opportunity loci. We are particularly interested in the manner in which individuals respond to differences in opportunity sets. It is the individual's human capital that determines the position of that individual's opportunity set. The most pertinent human-capital characteristic is education; race and sex are also important determinants of earnings capacity. These three variables together determine, for any degree of financial risk, the potential earnings of the individual. ${ }^{9}$

When differences in tastes are held constant, the response of individuals to different opportunity loci is open to question. Arrow's postulates of ( 1 ) decreasing absolute risk aversion and (2) increasing relative risk aversion help to clarify an answer. ${ }^{10}$ Decreasing absolute risk aversion has generally been interpreted to mean that as their wealth increases, people are willing to risk (given certain odds and payoffs) a larger absolute amount of that wealth. This behavior directly suggests that an individual with greater wealth, ceteris paribus, will choose an occupation with a larger standard deviation of earnings, provided that the probability distribution of returns is approximately normal. This postulate of decreasing absolute risk aversion is generally accepted.

Important for this study is the more controversial second postulate, which can best be demonstrated if earnings risk is measured in terms of a coefficient of variation in earnings. According to this postulate of increasing relative risk aversion, as wealth increases, the fraction of that wealth an

\footnotetext{
${ }^{9}$ Human-capital studies usually include age or experience as a determinant of earnings capacity; how. ever, age is irrelevant in a lifetime choice model.

${ }^{10}$ Kenneth J. Arrow, Essays in the Theory of RiskBearing (Chicago: Markham, 1971), pp. 90-120.
}

individual is willing to risk decreases. A direct implication is that an individual with greater wealth will choose an occupation with a small coefficient of variation. Holding constant the level of nonhuman wealth and the taste for risk, individuals with higher levels of education will choose jobs with lower risk. Indeed, any factor that tends to increase human capital and earnings capacity prior to a career choice should lead to individuals' choosing a lower degree of risk, if the assumption of increasing relative risk aversion is correct. ${ }^{11}$ The validity of Arrow's second postulate has been questioned, however. Although Arrow cites empirical evidence in its favor, Stiglitz disputes the use of that evidence. ${ }^{12}$

The presence of race or sex discrimination will lower the earnings capacity and, hence, the opportunity set of individuals subject to such discrimination. The assumption of increasing relative risk aversion then leads to the conclusion that, when the taste for risk-taking is held constant, blacks and females will, ceteris paribus, choose riskier jobs.

Other factors may also affect risk choice. The existence of nonlabor income should affect the occupation-industry choice if increasing relative risk aversion is assumed, but the effect is ambiguous. Clearly, the presence of nonhuman wealth should lead to a job choice that provides a lower coefficient of variation of total income, but the effect of non-human wealth on the coefficient of variation of labor income-the subject of this study-is indeterminate.

The same can be said of the effect of a working spouse. Again if increasing rela-

\footnotetext{
"There has been some controversy as to whether the concave indifference-curve approach to risk analysis is consistent with Arrow's second postulate. Tobin has pointed out that the validity of the indifferencecurve approach is maintained if the distribution of possible outcomes is approximately normal. As we explain below, the normality assumption appears appropriate for the particular earnings-risk concept employed in this study. See James Tobin, "Comment on Borch and Feldstein," Review of Economic Studies, Vol. 36, No. 1 (January 1969), pp. 13-14.

${ }^{12}$ Joseph E. Stiglitz, "The Effects of Income, Wealth, and Capital Gains Taxation on Risk-Taking," Quarterly Journal of Economics, Vol. 83, No. 2 (May 1969), pp. $263-83$.
} 
tive risk aversion is assumed, the earnings of a working spouse should have a negative effect on the family's chosen coefficient of variation of total income but an indeterminate effect on the coefficient of variation of the household head's labor income. It is questionable, in fact, whether any empirically observable effect should be present, since the validity of the above explanation would depend on the assumption that the career choices of husbands and wives are jointly determined, a condition that is probably true in only a small minority of cases. Keeping this caveat in mind, we acknowledge the remote possibility exists that variability in the spouse's earnings may be a factor in the household head's job choice.

Labor-force participation by both spouses represents workers' only opportunity for diversification in the labor market (aside from moonlighting). A negative relation is expected here. If the family is assumed to be willing to bear only a certain amount of overall risk, then the less variable the spouse's income, the greater the amount of risk that can be undertaken by the household head in the selection of an occupation industry. The strength of that relation will depend on the covariance of the two jobs.

Finally, marital status itself may affect the choice of risk made by a household head. The non-insurable consequences of downside earnings risk may weigh more heavily in the decision making of a married than a single individual even if both individuals have the same taste for risk. This factor will be of empirical consequence only if it is true that by and large workers correctly anticipate their future marital status and take it into account when making their career choices.

A number of predictions are thus derived from the theory of utility maximization under the condition of increasing relative risk aversion. These predictions are tested in the following section.

\section{The Statistical Model and Data}

The following reduced-form regression model is used to test the propositions developed above concerning the choice of risk implicit in job selection:

$$
\begin{gathered}
\text { (4) } C V=\beta_{0}+\beta_{1} R A+\beta_{2} A C C D+\beta_{3} E D \\
(-) \quad(-) \quad(-) \\
+\beta_{4} R A C E+\beta_{5} S E X+\beta_{6} M A R S T \\
(-) \quad(-) \quad(-) \\
+\beta_{7} N L I N C+\beta_{8} S E A R N+\beta_{9} S C V+\xi, \\
\text { (?) (?) }
\end{gathered}
$$

where $C V$ represents a coefficient of variation measuring the earnings riskiness of the occupation-industry chosen by the household head; $R A$ is a measure of the worker's aversion to risk; $A C C D$ is the probability of incurring a work-related accident in that particular occupation-industry category; and $E D, R A C E$, and $S E X$ are the variables representing human capital and earnings capacity. $E D$ is the total formal education of the household head. $R A C E$ and $S E X$ are binary variables given a value of 1 for whites and males. MARST is a binary variable given a value of $l$ for a married household head whose spouse is present. NLINC is the worker's nonlabor income in the survey year. NLINC is not the ideal variable to use in measuring the effect of nonhuman wealth on career choice. The preferred measure-the individual's lifetime nonlabor income anticipated prior to career choice, independent of any nonlabor income generated as a return-to-savings from labor income-is unobtainable. We would expect, especially for older workers, that return-to-previous-savings constitutes the bulk of NLINC and is thus the result of the career choice, rather than an exogenous determinant of career choice. $S E A R N$ is the spouse's earnings; $S C V$ is the coefficient of variation of earnings in the spouse's occupation-industry category; and $\xi$ is a random error term assumed to be normally distributed.

Below each coefficient is its predicted sign, drawn from the model outlined in the previous section. Equation 4 is thus a reduced-form equation that explains labor market risk choice by including variables accounting for differences, across individuals, in opportunities and in tastes. Although the right-hand variables are treated as exogenous, the possibility of at least 
partial endogeneity exists. This partial endogeneity would seem to hold true particularly with regard to physical risk, which logically should be regarded as chosen jointly with financial risk. This caveat should be borne in mind in interpreting the empirical results.

Three data sources were used to obtain measures of the variables described in Equation 4: the 1972 Panel Study of Income Dynamics (PSID), produced by the Institute for Social Research of the University of Michigan; the 1970 Census 1-1000 Public Use Sample (1-1000 Sample); and the 1971 Health Interview Survey (HIS), conducted by the U.S. Department of Health, Education, and Welfare. The primary data source was the PSID, from which a sample was selected of 2,771 household heads between the ages of twenty-five and sixty-five inclusive. ${ }^{13}$

There were two reasons for limiting the sample to the twenty-five to sixty-five age group. First, the inclusion of younger workers would have contaminated the sample with numerous individuals who have jobs that do not reflect their ultimate choice of career occupation and industry, as well as with significant numbers of individuals who have not yet completed their formal education. Second, and more importantly, previous researchers have found that the non-normality of the income distribution disappears when the distribution is constructed separately by occupation for individuals in the twenty-five to sixty-five age range. ${ }^{14}$ This finding of normality is of considerable value, as it overcomes the objection raised to concave indifference-curve analysis in asset-return studies that was mentioned in footnote 11 above.

Each household head was assigned to one of six general occupational categories spe-

${ }^{13}$ The PSID contains observations for a sample of nearly 5,000 families. The reduction of sample size to 2,771 for this study was the result of deleting those outside the twenty-five to sixty-five age range, those in occupation-industry categories not compatible with the other data sources we used, and those self-employed or in the armed forces.

${ }^{14}$ For example, see Stanley Lebergott, "The Shape of the Income Distribution," American Economic Review, Vol. 59, No. 3 (June 1959), pp. $328-47$. cific to one of twenty-eight industry groupings. ${ }^{15}$ The earnings-risk characteristic of each of the resulting 168 occupation-industry categories was measured by a kind of coefficient of variation of earnings for each individual category. Measuring only a coefficient of variation in earnings for each of the 168 groups would clearly be inappropriate since it would include both the variation in earnings across individuals that is the result of systematic earnings-related variables (such as education and experience) and the variation that is the result of true risk. To purge the systematic, non-risk variation, we employed a separate earnings equation for each occupation-industry category. The coefficient of variation of the residuals about the regression line $(C V)$ was then calculated. The data used in this part of the analysis were taken from the 1-1000 Sample rather than the $P S I D$ in order to obtain more efficient estimates of each equation. The 89,387 individuals in the 1-1000 Sample are classified by occupation-industry category, and the following earnings equation was estimated separately for each of the 168 groups:

$$
\begin{gathered}
\text { (5) } \log (E A R N)=\alpha_{0}+\alpha_{1} E D+\alpha_{2}(E D)^{2} \\
+\alpha_{3} E X P+\alpha_{4}(E X P)^{2}+\alpha_{5} R A C E \\
+\alpha_{6} S E X+\xi
\end{gathered}
$$

where $E A R N$ represents each worker's annual earnings; $E X P$ is that worker's job experience estimated as age less years of education completed less five; and $\xi$ is a random error term assumed to be normally distributed.

An index of risk aversion, $R A$, for each household head was obtained from the PSID. That index is formulated on the basis of answers to an assortment of questions concerning the condition and insurance of automobiles owned, the use of seat belts, the household head's extent of medical insurance coverage, and his or her smoking and drinking habits. The index ranges from zero to nine, nine representing the highest degree of risk aversion. Feinberg used the index as a measure of risk aversion in a study

${ }^{15} \mathrm{~A}$ listing of the occupation-industry categories used is available from the authors upon request. 
of one aspect of labor market behaviorduration of job search-and it performed as predicted. ${ }^{16}$ Bellante and Link used it in a study of the choice of employment sector (public versus private) and also found the variable to perform as predicted. ${ }^{17}$

The physical risk associated with a particular occupation-industry category was measured as the mathematical probability of incurring a job-related accident ( $A C C D)$. This variable, like $C V$, can assume one of 168 distinct values. $A C C D$ was calculated from the HIS. From that sample of 64,441 individuals, the 40,633 classified as workers were selected and assigned to one of the 168 occupation-industry categories. From responses to the question "Did you have (within the year) an accident or injury at work?", the probability of a job-specific accident was calculated. This measure weights accidents equally regardless of their severity. An alternative measure, $A C C D_{\text {sev }}$, was calculated accordingly as the probability that an individual had had an accident or injury for which hospitalization was required. Both measures of physical risk are used in the following analysis. The coefficient of variation of the spouse's occupation-industry category, $S C V$, was measured analogously to $C V$.

\section{Empirical Results}

The ordinary least squares results corresponding to Equation 4 are reported in the first two columns of the table. The column

\footnotetext{
${ }^{16}$ Robert M. Feinberg, "Risk Aversion, Risk, and the Duration of Unemployment," Review of Econornics and Statistics, Vol. 49, No. 3 (August 1977), pp. $264-$ 71.

${ }^{17}$ Don Bellante and Albert N. Link, "Are Public Sector Workers More Risk Averse than Private Sector Workers?" Industrial and Labor Relations Review, Vol. 34, No. 3 (April 1981), pp. 408-12. The riskavoidance index is described and documented in James N. Morgan et al., A Panel Study of Income Dynamics: Tape Codes and Indexes, Vol. II (Ann Arbor: University of Michigan Survey Research Center, 1972), p. 791. A rather exhaustive examination of the risk-avoidance index is provided by Al Arterburn, "Correlates of a Risk Avoidance Index," in Greg J. Duncan and James N. Morgan, eds., Five Thousand American Families: Patterns of Economic Progress, Vol. III (Ann Arbor: University of Michigan Survey Research Center, 1976). pp. $351-382$.
}

labelled (1) uses $A C C D$ as the accident probability measure and the column labelled (2) uses $A C C D_{\text {sev }}$. Since the results of both columns are similar, only those in column 1 will be discussed.

The estimated coefficient on $R A$ is negative, as hypothesized, and significant at the .01 level. It would be misleading to attempt an economic interpretation of the value of the coefficient because of the manner in which $R A$ is constructed. The results nevertheless suggest that those individuals who are more risk averse choose jobs that are subject to less earnings risk, ceteris paribus.

The estimated coefficient on $A C C D$ is negative, as hypothesized, and significant at the .01 level. The results imply that a percentage-point increase in the probability of a job-related accident (of any degree of severity) decreases the earnings risk an individual will accept in an occupation-industry choice by about 2.4 percentage points. Using $A C C D_{s e v}$, the estimated coefficient implies that a percentage-point increase in the probability of a severe accident will decrease the earnings risk chosen by the individual by about 10.5 percentage points. As would be expected, the coefficient on $A C C D_{\text {sev }}$ is numerically greater than that on $A C C D$. The results with respect to $A C C D$ and $A C C D_{\text {sev }}$ should be interpreted with caution. Both are almost certainly highly correlated with the probability of a fatal accident, particularly $A C C D_{\text {sev }}$. They may, therefore, actually be measuring the effects of "unsafe" working conditions-whether of a severe, nonsevere, or fatal type- on the choice of earnings risk.

All three of the human-capital and earnings capacity variables-ED, $R A C E$, and $S E X$-have the negative signs predicted and are significant at the .01 level. The estimated coefficient on $M A R S T$ also has the predicted negative sign and is significant at the .01 level. NLINC is insignificant. The extent to which this insignificance is due to our inability to measure correctly the relevant variable is open to question. The coefficient of $S E A R N$ is positive and significant at the .0l level. The coefficient of $S C V$, as predicted, is negative. It is significant only at the .05 level in column 1 , however, 
Table. Results of Regressions Estimating Determinants of Earnings Variation Among Household Heads.

( $t$-statistics in parentheses)

Estimated Coefficients

\begin{tabular}{|c|c|c|c|c|}
\hline \multirow[b]{2}{*}{ Variables } & \multicolumn{2}{|c|}{ Annual Earnings } & \multicolumn{2}{|c|}{ Hourly Wages } \\
\hline & (1) & (2) & (3) & (4) \\
\hline Intercept & 6.41 & 6.00 & .2844 & .2692 \\
\hline RA & $\begin{array}{l}-.1013^{* *} \\
(-6.03)\end{array}$ & $\begin{array}{l}-.0915^{* *} \\
(-5.39)\end{array}$ & $\begin{array}{l}-.0055^{* *} \\
(-5.10)\end{array}$ & $\begin{array}{l}-.005)^{* *} \\
(-4.74)\end{array}$ \\
\hline ACCD & $\begin{array}{l}-2.40 * * \\
(-9.24)\end{array}$ & - & $\begin{array}{l}-.1281^{* *} \\
(-7.66)\end{array}$ & - \\
\hline $\mathrm{ACCD}_{\mathrm{sev}}$ & - & $\begin{array}{l}-10.49 * * \\
(-4.66)\end{array}$ & - & $\begin{array}{l}-1.34^{* *} \\
(-9.37)\end{array}$ \\
\hline ED & $\begin{array}{l}-.1039^{* *} \\
(-13.05)\end{array}$ & $\begin{array}{c}-.0919^{* *} \\
(-11.62)\end{array}$ & $\begin{array}{l}-.0045^{* *} \\
(-8.85)\end{array}$ & $\begin{array}{l}-.0043^{* *} \\
(-8.63)\end{array}$ \\
\hline RACE & $\begin{array}{l}-.4307^{* *} \\
(-7.49)\end{array}$ & $\begin{array}{l}-.4012^{* *} \\
(-6.90)\end{array}$ & $\begin{array}{l}-.0314^{* *} \\
(-8.47)\end{array}$ & $\begin{array}{l}-.0293^{* *} \\
(-7.94)\end{array}$ \\
\hline SEX & $\begin{array}{l}-.7588^{* *} \\
(-6.79)\end{array}$ & $\begin{array}{l}-.7910^{* * *} \\
(-6.99)\end{array}$ & $\begin{array}{l}-.0893^{* *} \\
(-12.39)\end{array}$ & $\begin{array}{l}-.0873^{* *} \\
(-+2.16)\end{array}$ \\
\hline MARST & $\begin{array}{l}-.2746^{* *} \\
(-2.55)\end{array}$ & $\begin{array}{l}-.3097 * * \\
(-2.85)\end{array}$ & $\begin{array}{l}-.0203^{* *} \\
(-2.94)\end{array}$ & $\begin{array}{l}-.0211^{* *} \\
(-3.07)\end{array}$ \\
\hline NLINC & $\begin{array}{l}.0000+ \\
(.75)\end{array}$ & $\begin{array}{l}.0000+ \\
(.89)\end{array}$ & $\begin{array}{l}.0000+ \\
(.45)\end{array}$ & $\begin{array}{l}.0000+ \\
(.47)\end{array}$ \\
\hline SEARN & $\begin{array}{l}.0373^{* *} \\
(2.77)\end{array}$ & $\begin{array}{l}.0359^{* *} \\
(2.63)^{2}\end{array}$ & $\begin{array}{l}.0005 \\
(.70)\end{array}$ & $\begin{array}{l}.0004 \\
(.59)\end{array}$ \\
\hline $\mathrm{SCV}$ & $\begin{array}{l}-.0261^{*} \\
(-2.23)\end{array}$ & $\begin{array}{c}-.0227 \\
(-1.91)\end{array}$ & $\begin{array}{l}-.0109 \\
(-.65)\end{array}$ & $\begin{array}{l}-.0090 \\
(-.54)\end{array}$ \\
\hline $\mathrm{R}^{2}$ & .270 & .253 & .339 & .346 \\
\hline F-level & 113.37 & 103.96 & 157.32 & 162.09 \\
\hline
\end{tabular}

* Significant at the .05 level in a two-tailed test.

**Significant at the .01 level in a two-tailed test.

and misses the .05 level in column 2 .

The results of columns 1 and 2 of the table strongly suggest a tendency of labor market participants to respond systematically to the variety of implicit contracts offered in the labor market. It should be noted, though, that the extent of unemployment in an occupation-industry category is a primary source of variation of earnings in that category. Although our arguments apply with equal validity to any source of variation in earnings, our findings would be substantially less interesting if $C V$ were a mere proxy for the unemployment rate in a particular category since the human-capital and demographic determinants of unemployment have been examined in great detail elsewhere. ${ }^{18}$ The equations in columns 1 and 2 were reestimated to examine this possibility by using the adjusted coefficient of variation of hourly wage rates instead of annual earnings as the dependent variable. These results are presented in columns 3 and 4 of the table (with column 3 analagous to column $\mathrm{l}$ and column 4 to

\footnotetext{
${ }^{18}$ Moreover, the literature on implicit contracting seems more directly concerned with wage-rate stability than with overall earnings stability, though the opposite is true in the usual "textbook" labor economics discussion.
} 
column 2). The results conform in a qualitative manner quite closely to those of the equations using annual earnings, except for the fact that $S C V$ and $S E A R N$ become insignificant. $R^{2}$ is significantly raised. These findings suggest that the response of labor market participants to risk is a generalized response and is not limited to earnings variation attributable to different unemployment rates. ${ }^{19}$

\section{Concluding Remarks}

The development of implicit contract theory has provided a rationale, from the employer side, for the existence of a menu of implicit contracts from which workers can choose to trade off mean earnings for earnings stability. The results of this study lead to the conclusion that labor market participants demonstrate a tendency to perceive and act upon the menu of choices before them. This finding adds some strength to the contention that in the highly idiosyncratic labor markets prevalent in the U.S. economy, the existence of that possible trade-off may be Pareto-superior to a regime of auction markets. Our conclusions fall under categories pertaining to the findings and methodology of this study and the implications of our findings for other labor market studies.

The findings. Using the PSID index of risk avoidance as our measure of taste for risk aversion, we find that those workers who are more risk averse exhibit a tendency to choose less financially risky jobs, ceteris paribus. Furthermore, workers with a given degree of risk aversion exhibit a willingness to trade off physical risk against financial risk. It appears that the average worker, at the margin, would accept a 10.5 percent higher degree of variability in earnings (in

\footnotetext{
${ }^{19}$ Several other versions of Equation 4 were estimated. One version, for example, limited the sample to male heads of households. These altemative estimations did not produce results materially different from those reported in the table. In another set of specifications, we entered $R A$ as a set of dummy variables. Alternative versions were considered that included from one to six such variables. In all cases, the order of magnitude was as predicted, but $\mathrm{R}^{2}$ was raised by about one percentage point or less over the version reported in the table. These results are available from the authors.
}

terms of a coefficient of variation) in exchange for a one percent lower probability of a severe accident. Provisions for both safer working conditions and earnings stability are costly to firms. It is apparent, nevertheless, that firms can induce workers to accept a certain degree of physical risk not only by offering a higher wage, but also by offering earnings stability. The relative attractiveness of the two approaches will vary across industries, of course, but whenever a disparity exists between workers' marginal rates of substitution and firms' marginal rates of transformation, potential gains from making a trade exist. Indeed, the negative correlation we found between physical risk and earnings risk by occupation-industry category indicates that to some degree firms are compensating for physical risk by offering less earnings risk. Of course any undesirable attribute of a job will require compensation, and a wage premium is but one form of compensation. This fact should be borne in mind in any study of compensating wage differentials. It seems quite reasonable to assume, on the other hand, that compensation for safety hazards will be at least partly in the form of earnings stability, since both attributes (safety and earnings stability) relate to the psychological desire to avert risk.

Arrow's second postulate of increasing relative risk aversion served as the maintained hypotheses of this study; and the strongest predictions derived here were negative relations between earnings-capacity variables (education, race, and sex) and the degree of earnings risk implicit in the job choice. The significantly negative coefficients for these variables are thus uniformly consistent with increasing relative risk aversion and therefore provide indirect evidence from the labor market (the only such evidence of which we are aware) in support of the second postulate.

The methodology. The most common approach in cross-sectional studies of individual behavior that employ the utility-maximization framework is to derive a reducedform equation containing ( 1 ) a set of independent variables to control for differences in economic constraints or oppor- 
tunities across individuals and (2) a set of independent variables of a demographic nature intended partially to control for differences in tastes across demographic groups. The implicit assumption (or perhaps hope) in using the second set of variables is that within demographic groups the effects of differing economic constraints will swamp differences in tastes. One problem in using this set is that demographic variables (such as race, age, and sex) perform "double duty" since they capture differences in tastes as well as differences in constraints; the scope of conclusions that can be drawn is therefore limited. We have departed from this standard methodology by using a more direct proxy for the one taste parameter-risk aversion-most closely tied to our dependent variable, risk choice. Although psychologists and sociologists have traditionally placed great reliance on attitude surveys, we share the suspicions of many economists regarding their use. Surely the PSID measure could be improved upon; to our knowledge, however, the PSID is the only large economics micro data set that contains any sort of measure of risk aversion. Our results with this variable should be treated cautiously; but considered together with Feinberg's, they suggest the potential fruitfulness of including in micro data sets attempted measures of this and other psychological variables such as internal rates of time preference. The PSID index of risk avoidance in particular should be subjected to close study before it is accepted more than tentatively. In the meantime, some confidence in its validity will be gained if it is successfully employed in other unrelated studies of economic behavior.

Implications. Our findings have implications for other labor market studies. The literature abounds with studies of race and sex discrimination that compare black/ white or male/female earnings ratios after controlling for as many productivity-related variables as possible. It is sometimes alleged that the use of the residual difference overestimates the effect of discrimination on earnings. ${ }^{20}$ Our results may be interpreted as suggesting that these studies in one respect underestimate the impact. The negative coefficients we found for race and sex suggest that blacks and women who are heads of households partially offset the effects of reduced earnings opportunities by accepting greater risk, for which they are compensated. The victims are in effect "repurchasing" some of the earnings potential taken away by discrimination by accepting riskier jobs than those they otherwise would accept. To date, studies of discrimination do not take this compensating differential into account; ${ }^{21}$ nor do they take into account the compensating differentials associated with other unfavorable job characteristics accepted as mitigation of discrimination's effects.

A similar remark can be made with respect to studies such as Thaler and Rosen's of wage differentials that compensate for differences in occupational safety. Our results suggest that employers compensate for physical hazards not only by paying higher wages, but also by providing greater wage stability. If this implication is correct, such studies are, ceteris paribus, underestimating the compensating differential (in terms of employers' costs) necessary to induce workers to accept an increment of physical risk.

\footnotetext{
${ }^{20}$ For example, see Joe C. Davis and Carl M. Hubbard, "On the Measurement of Discrimination against Women," American Journal of Economics and Sociology, Vol. 38, No. 3 (July 1979), pp. 287-91.

"One possible remedy to this problem would be to include the value of our dependent variable, $C V$, in the earnings equations used in discrimination studies.
} 
Copyright of Industrial \& Labor Relations Review is the property of Cornell University and its content may not be copied or emailed to multiple sites or posted to a listserv without the copyright holder's express written permission. However, users may print, download, or email articles for individual use. 